\title{
Feeding responses of hybrids and the inheritance of host-use traits in leaf feeding beetles (Coleoptera: Chrysomelidae)
}

\author{
MARK C. KEESE* \\ Department of Ecology and Evolution, SUNY at Stony Brook, Stony Brook, NY 11794-5245, U.S.A.
}

\begin{abstract}
This paper examines the responses of $F_{1}$ hybrids between two closely related chrysomelid beetles to the host plants of their parents. Ophraella notulata (NTL) and O. slobodkini (SLB) feed exclusively on the asteraceous plants Iva frutescens and Ambrosia artemisiifolia, respectively. Virgin males and females were crossed in all possible combinations and their progeny were tested for host preference, host acceptability and larval survival on each host plant. $\mathrm{NTL} \times \mathrm{SLB}$ (female $\times$ male) pairings did not produce viable eggs. Comparisons of larval responses between the crosses showed strong dominance for most traits measured. Hybrid larvae $(\mathrm{SLB} \times \mathrm{NTL}$ ) resembled SLB for host preference and the acceptability of $A$. artemisiifolia, but they resembled NTL for larval survival. The acceptability of $I$. frutescens appeared to be inherited additively. These results suggest that the genes responsible for recognizing and accepting the two host plants and for host preference and performance are inherited independently. More detailed studies of the inheritance of host-use traits are needed to determine how common such dominance patterns are and how many loci control such traits, both of which have important implications for theories of how host plant associations evolve.
\end{abstract}

Keywords: Chrysomelidae, dominance, host preference, hybridization, larval performance, phytophagous insects.

\section{Introduction}

Successful utilization of a host plant by a phytophagous insect involves three major steps: location and acceptance for oviposition by gravid females, acceptance of the plant for feeding by larvae and the physiological ability of larvae to survive and develop while consuming the plant's tissues (Futuyma \& Peterson, 1985; Singer, 1986; Via, 1986). Whereas there has been much work recently on phenotypic and genetic variation within and among populations for these traits on both natural and novel host plants (Via, 1984a,b; Futuyma \& Philippi, 1987; Jaenike, 1989; Karowe, 1990; Kibota \& Courtney, 1991; Futuyma et al., 1993b; Keese, 1994) comparatively few studies have examined how traits associated with host use (i.e. oviposition preference, larval consumption, larval growth and survival) are inherited (Schneider \& Roush, 1986; Hagen, 1990; Thompson

\footnotetext{
*Current address: Department of Biology, University of Delaware, Newark, DE 19716, U.S.A.
}

et al., 1990; Waldvogel \& Gould, 1990; Scriber et al., 1991).

Early studies of oviposition preference and offspring performance in hybrids between host races or species that use different host plants indicated that hybrid larvae often would feed only on the host of one parent (Denso, 1909; Field, 1914; Harrison, 1926 as in Dethier, 1954). These and more recent studies of the inheritance of host-use traits have been performed almost exclusively on Lepidoptera. Their unusual pattern of sex determination (females are $\mathrm{XO}$, males are $\mathrm{XX}$ ) has no doubt facilitated recent studies by allowing sex linkage to be relatively easily determined. For example, Thompson (1988) studied a pair of swallowtail butterflies in the genus Papilio that differ in the plant families on which the hemizygous females oviposit. Papilio oregonius is a specialist on Artemisia (Asteraceae) whereas P. zelicaon oviposits on several species in the family Apiaceae (probably the ancestral condition). Oviposition preference of reciprocal hybrids tended toward the paternal rather than the maternal species, suggesting sex linkage. Thompson et al. (1990) extended this 
study to examine the inheritance of larval performance. Hybrids, regardless of which direction the cross was performed, survived well on the hosts of both parents. There was no indication that the genes for larval performance are on the $\mathrm{X}$ chromosome as are the genes for oviposition preference. Thus the two traits are independently inherited and there is no evidence that 'pleiotropy or physical linkage of loci for oviposition preference and larval performance seem to be involved in the evolution of interspecific differences in host use between these two species' (Thompson et al., 1990).

Other studies in Papilio suggested sex linkage for oviposition preference (Scriber et al., 1991) although the $F_{1}$ hybrids can survive and grow on both parental hosts (Hagen, 1990). Alternatively, the reciprocal $F_{1}$ hybrids of two populations of Heliothis virescens with different oviposition preferences were intermediate between the parental strains, suggesting that oviposition preference is inherited additively (Schneider \& Roush, 1986; Waldvogel \& Gould, 1990). Recently, Katakura \& Hosogai (1994) examined performance of hybrid coccinelid beetles on the hosts of the parental species. $F_{1}$ hybrids from crosses in both directions were capable of survival and growth on both parental hosts. They did not report data on $F_{2}$ or backcross generations.

Here I will compare the responses of $F_{1}$ hybrid larvae of the closely related leaf feeding beetles Ophraella slobodkini and $O$. notulata (Coleoptera: Chrysomelidae) to their parental host plants (Ambrosia artemisiifolia and Iva frutescens, respectively) with larvae from homospecific crosses to examine the mode of inheritance of behavioural and physiological traits associated with host use.

\section{Methods}

\section{Study organisms}

Ophraella notulata (Fabricius) and $O$. slobodkini (Futuyma) are sister taxa with an estimated divergence time based on mitochondrial DNA evidence of six million years (Funk et al., 1995). Ophraella notulata feeds exclusively as larvae and adults on $I$. frutescens, a shrubby perennial that grows in salt marshes along the Atlantic and Gulf coasts of the eastern U.S.A. The geographical range of $O$. notulata extends from the Gulf Coast to Long Island, NY, along coastal marshes. Ophraella slobodkini, a newly described species (Futuyma, 1991), feeds exclusively, as far as known, on the early successional weedy annual $A$. artemisiifolia. It has been collected only throughout Florida and in extreme southern Georgia. Adults of these two species are very similar morphologically but can be reliably distinguished by starch gel electrophoresis (Futuyma, 1991). In Florida, where their geographical ranges overlap, some populations exist sympatrically (within a few hundred metres) without any evidence of introgression or lack of host fidelity (Futuyma \& Keese, unpublished data).

\section{Crossing design}

In September 1991, I collected 50 gravid females of O. slobodkini from Tall Timbers Research Station (TTRS), Tallahassee, FL, and 50 gravid females of $O$. notulata from St. Marks National Wildlife Refuge, St. Marks, FL. These females produced eggs in the laboratory and larvae were reared in cohorts of 10 on whole potted plants (greenhouse-grown under 16:8 LD) of their native host plant species. Beetles were reared and tested under fluorescent light in a growth chamber at $16: 8 \mathrm{LD}, 25^{\circ} \mathrm{C}$ and approximately 50 per cent relative humidity. Upon eclosion, the adults were sexed and kept separately until all adults had eclosed, a range of 6 days. On 30 and 31 October, heterospecific pairings of single females and males (both virgin) were placed in individual $90 \mathrm{~mm}$ diameter Petri dishes lined with moistened filter paper but otherwise empty (i.e. no plant material). Twenty-five females of $O$. slobodkini (hereafter SLB) were crossed with $O$. notulata (hereafter NTL) males (SLB $\times$ NTL, throughout this paper I will use female $\times$ male to denote both homoand heterospecific crosses) and 28 females of NTL were crossed with SLB males $(\mathrm{NTL} \times \mathrm{SLB})$. Pairs were observed continuously for $9 \mathrm{~h}$ on each day and copulations were recorded. At the end of each day, males and females were separated and each was given a fresh leaf fragment of their native host. On 1 November, females that had not yet mated (11 SLB, 16 NTL) were paired with a conspecific male $(\mathrm{SLB} \times \mathrm{SLB}, \quad \mathrm{NTL} \times \mathrm{NTL})$ and data recorded as above.

In September 1992, approximately 40-50 mated females of each species were collected from the same localities as in 1991. These stock populations were reared in the laboratory for two generations using the same protocol as in 1991. On 2 December, 20 individual virgin females of each species were placed individually in $90 \mathrm{~mm}$ diameter Petri dishes lined with moistened filter paper with two males of the other species, but without leaf material. Copulations were recorded every $15 \mathrm{~min}$ for $8 \mathrm{~h}$ and the beetles were left together for $24 \mathrm{~h}$. On 3 December, eight virgin NTL and 10 virgin SLB females were 
placed together with conspecific males for $24 \mathrm{~h}$ as above.

\section{Feeding responses}

In both years, mated females were isolated in $90 \mathrm{~mm}$ diameter Petri dishes with fresh leaf material provided as needed (every 2 or 3 days). As eggs were deposited, the eggs were removed from the leaf and moved to a clean Petri dish lined with moistened filter paper. This was carried out to prevent any early larval conditioning effects from exposure to the maternal host plant. In 1991, 25 first instar larvae from each $\mathrm{SLB} \times \mathrm{NTL}$ pair that produced eggs were placed individually into a $60 \mathrm{~mm}$ diameter Petri dish lined with moistened filter paper (NTL $\times$ SLB pairings did not produce viable eggs). Ten larvae each from SLB $\times$ SLB and NTL $\times$ NTL pairs were similarly set up as controls. The sample size of the controls was relatively small because previous experiments had shown that there is little variation in larval feeding perference between $A$. artemisiifolia and I. frutescens in either of these two species (Keese, 1994). Two circular leaf discs (6 mm diameter) of both host plants were placed in each dish as a choice test. The two host species were alternated in a diamond-shaped array and the larva was initially placed in the centre. Successive dishes within each treatment were offset by $90^{\circ}$ to minimize possible position effects. Feeding response was quantified as leaf area consumed (the number of ocular grid units with a dissecting microscope at $12 \times$ where 100 units $=12.96 \mathrm{~mm}^{2}$ ) after $48 \mathrm{~h}$. This experiment provides a measure of larval feeding preference of heterospecific crosses relative to homospecific crosses.

In 1992, 230 newly-hatched larvae from each pair that produced eggs (homo- and heterospecific) were placed in Petri dishes as in 1991, except that 10 dishes received two leaf fragments (an ad libidum amount) of $I$. frutescens only and 10 dishes received a similar amount of $A$. artemisiifolia only. Feeding response was measured as before. This experiment provides a measure of host acceptibility to larvae from heterospecific crosses relative to homospecific crosses.

\section{Larval survival}

In 1991, 40 newly hatched larvae from each heterospecific cross were split into four cohorts of 10 larvae each. Two cohorts were placed on individually potted plants of $A$. artemisiifolia $(15-20 \mathrm{~cm}$ tall) whereas the other two were placed on individually potted plants of $I$. frutescens $(15-20 \mathrm{~cm}$ tall). The plants were surrounded by a $6 \mathrm{~cm}$ diameter, $23 \mathrm{~cm}$ tall plastic tube with a nylon mesh screen for a top. Survival was scored as the number of larvae alive at 15 days. In 1992, four cohorts of 10 larvae each from each cross (homo- and heterospecific) were placed on individually potted plants $(15-20 \mathrm{~cm}$ tall) as described above. Survival was scored after 15 days. In neither year was larval growth data recorded. Larvae were not weighed when survival was scored because the aim was to obtain $F_{1}$ adults for further genetic studies without adversely affecting subsequent survival by removing larvae from the plant.

\section{Statistical analyses}

Host preferences of larvae when given a choice between $A$. artemisiifolia and I. frutescens in 1991 were analysed by calculating the difference between the amount of leaf material consumed (A. artemisiifolia $-I$. frutescens) and analysing these paired differences for differences between crosses, in a one-way ANOVA using PROC GLM, SAS version 6 . Tukey's test for unplanned comparisons was used to compare means across treatments. Student's $t$-tests for paired comparisons (Sokal \& Rohlf, 1981) were performed for each treatment separately to determine whether larvae of a particular parentage had a preference when given a choice between the two host plant species. That is, was the difference between the amount consumed of the two plants significantly different from zero?

The acceptability of $A$. artemisiifolia and $I$. frutescens to larvae in 1992 no-choice tests (measured as the mean of log transformed consumption scores per family) was analysed by two-way ANOVA with interaction where the mating cross (SLB $\times$ SLB, $\mathrm{SLB} \times \mathrm{NTL}, \mathrm{NTL} \times \mathrm{NTL})$ and the host plant species (A. artemisiifolia and I. frutescens) were fixed factors. Differences among crosses for each host plant were also analysed separately by one-way ANOVA. The $F$-ratio for these latter tests was calculated using the $\mathrm{MS}_{\text {error }}$ from the two-way ANOVA (Sokal \& Rohlf, 1981). Tukey's test for unplanned comparisons was used to compare means across treatments.

Differences between host plants in survival of hybrid larvae in 1991 were analysed by one-way ANOVA. Larval survival in 1992 was analysed by two-way ANOVA with interaction where mating cross (female $\times$ male) and host plant species $(A$. artemisiifolia and I. frutescens) were fixed factors. Additional tests were performed as for the acceptability experiments above.

(c) The Genetical Society of Great Britain, Heredity, 76, 36-42. 


\section{Results}

\section{Host preference}

The mean differences between consumption of $A$. artemisiifolia and $I$. frutescens for each mating cross are presented in Table 1 . There was significant variation in host preference between the offspring of the different crosses $\left(F_{2,204}=24.53, P<0.001\right)$. Larvae from SLB $\times \operatorname{SLB} \quad\left(t_{9}=13.97, \quad P<0.001\right) \quad$ and SLB $\times$ NTL $\quad\left(t_{186}=16.55, \quad P<0.001\right)$ crosses both strongly preferred $A$. artemisiifolia over $I$. frutescens whereas NTL $\times$ NTL larvae strongly preferred $I$. frutescens over $A$. artemisiifolia $\left(t_{9}=5.22, P<0.001\right)$. Furthermore, SLB $\times$ SLB and SLB $\times$ NTL larvae were not significantly different from each other in the difference between their consumption of the two host plants, but both were significantly different from NTL $\times$ NTL larvae. Thus $F_{1}$ hybrids of SLB $\times$ NTL copulations preferred the host plant of their maternal species for feeding.

\section{Host acceptability}

The means and standard errors of larval consumption in a no-choice test from each mating cross on each host plant species are presented in Table 2 .

Table 1 Host preference of larvae from SLB $\times$ SLB, $\mathrm{SLB} \times \mathrm{NTL}$ and NTL $\times$ NTL crosses

\begin{tabular}{|c|c|c|c|c|}
\hline Mating cross & \multicolumn{2}{|c|}{ Difference } & \multicolumn{2}{|c|}{ Preference } \\
\hline $\mathrm{SLB} \times \mathrm{SLB}$ & \multicolumn{2}{|c|}{$52.80 \pm 3.78(10)^{\mathrm{a}}$} & \multicolumn{2}{|c|}{$\mathrm{ART}, t=13.97^{* * *}$} \\
\hline $\mathrm{SLB} \times \mathrm{NTL}$ & \multicolumn{2}{|c|}{$39.89+2.41(187)^{a}$} & \\
\hline NTL $\times N T L$ & \multicolumn{2}{|c|}{$-30.70 \pm 5.88(10)^{\mathrm{b}}$} & \multicolumn{2}{|c|}{$\begin{array}{l}\text { ART, } t=16.55^{* * *} \\
\text { IVA, } t=5.22^{* * *}\end{array}$} \\
\hline Source & d.f. & MS & $F$ & $P$ \\
\hline Mating cross & 2 & 24946.05 & 24.53 & $* * *$ \\
\hline Error & 204 & 1017.11 & & \\
\hline
\end{tabular}

NTL, Ophraella notula; SLB, O. slobodkini.

For each larva, the difference in the amount consumed between the two plants was calculated as (Ambrosia artemisiifolia-Iva frutescens). Means plus or minus one standard error of the mean for difference in consumption between $A$. artemisiifolia and $I$. frutescens are given for each mating cross.

Numbers in parentheses are sample sizes.

Means with the same letter are not significantly different from each other by Tukey's test for unplanned comparisons. Preference was determined by a $t$-test for paired comparisons. ART, $A$. artemisiifolia; IVA, $I$. frutescens. For the summary ANOVA table paired differences between consumption were analysed by oneway ANOVA for differences between mating crosses. ***$P<0.001$.
There was a significant interaction between the cross (homo- and heterospecific) and the host plant species (A. artemisiifolia and $I$. frutescens) $\left(F_{2,45}=38.60, P<0.001\right)$. When the data are analysed for each host species separately, there are significant differences between crosses on both $A$. artemisiifolia $\left(F_{2,45}=4.18, P<0.05\right)$ and $I$. frutescens $\left(F_{2,45}=52.48\right.$, $P<0.001)$. On $A$. artemisiifolia, SLB $\times$ SLB and $\mathrm{SLB} \times$ NTL larvae had significantly higher consumption than NTL $\times$ NTL larvae, but there was no difference between the former groups. Thus, as for larval host preference in 1991, $F_{1}$ hybrid larvae resemble their maternal parent in their response to the maternal host plant. On I. frutescens, however, SLB $\times$ NTL larvae and NTL $\times$ NTL lavae had significantly higher consumption than SLB $\times$ SLB larvae but did not differ from each other. Thus, contrary to the results when tested on the maternal host plant,

Table 2 Acceptability of Ambrosia artemisiifolia and Iva frutescens to larvae of homo- and heterospecific crosses in a no-choice test

\begin{tabular}{lcccc}
\hline Mating cross & \multicolumn{2}{c}{ A. artemisiifolia } & \multicolumn{2}{c}{ I. frutescens } \\
\hline SLB $\times$ SLB & $35.95 \pm 1.76(85)^{\mathrm{a}}$ & $3.12 \pm 0.53(88)^{\mathrm{a}}$ \\
SLB $\times$ NTL & $42.09 \pm 2.32(89)^{\mathrm{a}}$ & $16.06 \pm 1.18(80)^{\mathrm{b}}$ \\
NTL $\times$ NTL & $26.27 \pm 2.14(80)^{\mathrm{b}}$ & $25.55 \pm 1.57(80)^{\mathrm{b}}$ \\
Source & d.f. & MS & $F$ & $P$ \\
Cross & 2 & 0.755 & 18.17 & $* * *$ \\
Host & 1 & 3.218 & 77.40 & $* * *$ \\
Cross $\times$ host & 2 & 1.605 & 38.60 & $* * *$ \\
Error & 45 & 0.042 & & \\
A. artemisiifolia & & & & \\
Source & d.f. & MS & $F$ & $P$ \\
Cross & 2 & 0.174 & 4.18 & $*$ \\
Error & 45 & 0.042 & & \\
$I$. frutescens & \multicolumn{5}{c}{ d.f. } & MS & $F$ & $P$ \\
Source & 2 & 2.182 & 52.48 & $* * *$ \\
Cross & 45 & 0.042 & & \\
Error & & &
\end{tabular}

NTL, Ohraella notula; SLB, O. slobodkini.

Consumption of newly hatched larvae measured after $48 \mathrm{~h}$ (log transformed) was analysed by two-way ANOVA with interaction where mating cross $(\mathrm{SLB} \times \mathrm{SLB}, \mathrm{SLB} \times \mathrm{NTL}$, NTL $\times$ NTL) and host plant species (A. artemisiifolia and I. frutescens) were fixed factors.

Means and standard errors for each mating cross on each host plant species are for untransformed data.

Numbers in parentheses are sample sizes.

Means with the same letter within each column are not significantly different from each other by Tukey's test for unplanned comparisons from one-way ANOVAs for each host separately on log transformed data.

${ }^{*} P<0.05$, *** $P<0.001$. 
when tested on the paternal host plant, $F_{1}$ hybrids resembled their paternal parent.

\section{Larval survival}

The means and standard errors for larval survival on $A$. artemisiifolia and $I$. frutescens for each hybrid family as well as the grand mean of all families in 1991 are presented in Table 3. Survival of $\mathrm{SLB} \times \mathrm{NTL}$ hybrid larvae on the two host plants was higher on $I$. frutescens $\left(F_{1,24}=3.67, P=0.06\right)$, although marginally nonsignificant. The means and standard errors for larval survival in 1992 of each mating cross $(\mathrm{SLB} \times \mathrm{SLB}, \mathrm{SLB} \times \mathrm{NTL}, \mathrm{NTL} \times \mathrm{NTL})$ on $A$. artemisiifolia and $I$. frutescens are presented in Table 4. There was a significant interaction between the mating cross and host plant species $\left(F_{2,40}=22.59, \quad P<0.001\right)$. There were significant differences between mating crosses for survival on $I$. frutescens $\left(F_{2,40}=23.85, P<0.001\right)$ but not on $A$. artemisiifolia $\left(F_{2,40}=2.98\right.$, NS). Tukey's test for unplanned comparisons on $I$. frutescens showed that NTL $\times$ NTL and SLB $\times$ NTL larvae had a higher survival than SLB $\times$ SLB larvae. As for host acceptability, hybrid larvae on $I$. frutescens resemble their paternal parent in their survival response.

Table 3 Survival of Ophraella slobodkini $\times O$. notula hybrid larvae on Ambrosia artemisiifolia and Iva frutescens in 1991

\begin{tabular}{|c|c|c|c|c|}
\hline Family & \multicolumn{2}{|c|}{ A. artemisiifolia } & \multicolumn{2}{|c|}{ I. frutescens } \\
\hline 2 & \multicolumn{2}{|c|}{$0.367 \pm 0.03$} & \multicolumn{2}{|c|}{$0.839 \pm 0.06(2)$} \\
\hline 7 & \multicolumn{2}{|c|}{$0.450 \pm 0.25(2)$} & \multicolumn{2}{|c|}{$0.450 \pm 0.15(2)$} \\
\hline 9 & \multicolumn{2}{|c|}{$0.200 \pm 0.10(2)$} & \multicolumn{2}{|c|}{$0.750 \pm 0.15(2)$} \\
\hline 15 & \multicolumn{2}{|c|}{$0.500 \pm-(1)$} & \multicolumn{2}{|c|}{$0.400 \pm 0.10(2)$} \\
\hline 21 & \multicolumn{2}{|c|}{$0.300 \pm 0.10(2)$} & \multicolumn{2}{|c|}{$0.350 \pm 0.05(2)$} \\
\hline 24 & \multicolumn{2}{|c|}{$0.450 \pm 0.15(2)$} & \multicolumn{2}{|c|}{$0.350 \pm 0.05(2)$} \\
\hline 25 & \multicolumn{2}{|c|}{$0.550 \pm 0.15(2)$} & \multicolumn{2}{|c|}{$0.900 \pm-(1)$} \\
\hline Grand mean & \multicolumn{2}{|c|}{$0.395 \pm 0.12(13)$} & \multicolumn{2}{|c|}{$0.552 \pm 0.17$} \\
\hline Source & d.f. & MS & $F$ & $P$ \\
\hline Host & 1 & 0.211 & 3.67 & 0.06 \\
\hline Error & 24 & 0.057 & & \\
\hline
\end{tabular}

Data are the mean proportion of larvae surviving to 15 days for each of two replicate rearing containers on each host plant species.

The proportions were square root transformed prior to analysis by one-way ANOVA.

Means and standard errors are for untransformed proportion surviving.

Numbers in parentheses are sample sizes (the number of replicate rearing containers).

Summary ANOVA is for differences in survival between host plants.

\section{Discussion}

Successful hybridization occurred asymmetrically, that is viable larvae were produced only in the $\mathrm{SLB} \times \mathrm{NTL}$ direction $(\mathrm{NTL} \times \mathrm{SLB}$ eggs failed to hatch). Furthermore, only nine of those larvae (out of a 2-year total of approximately 650) pupated into adults. Thus there appears to be $F_{1}$ hybrid inviability. That hybrid offspring of $O$. slobodkini females and $O$. notulata males survived in relatively high numbers until pupation (see survival data) suggests that specific genes that function during metamorphosis were involved in this inviability. Indeed, the few adults that did eclose were malformed and died within 2 or 3 days without feeding.

Nevertheless, the results obtained on these hybrid larvae are interesting. Comparisons between the

Table 4 Larval survival of homo- and heterospecific crosses reared on either Ambrosia artemisiifolia or Iva frutescens

\begin{tabular}{|c|c|c|c|c|}
\hline Mating cross & \multicolumn{2}{|c|}{ A. artemisiifolia } & \multicolumn{2}{|c|}{ I. frutescens } \\
\hline $\mathrm{SLB} \times \mathrm{SLB}$ & \multicolumn{2}{|c|}{$0.858 \pm 0.046(12)^{\mathrm{a}}$} & \multicolumn{2}{|c|}{$0.082 \pm 0.036(12)^{\mathrm{a}}$} \\
\hline SLB $\times$ NTL & \multicolumn{2}{|c|}{$0.667+0.076(17)^{a}$} & \multicolumn{2}{|c|}{$0.650 \pm 0.046(16)^{\mathrm{b}}$} \\
\hline NTL $\times$ NTL & \multicolumn{2}{|c|}{$0.662 \pm 0.070(16)^{a}$} & \multicolumn{2}{|c|}{$0.672 \pm 0.051(16)^{\mathrm{b}}$} \\
\hline Source & d.f. & MS & $F$ & $P$ \\
\hline Cross & 2 & 0.339 & 5.68 & $* *$ \\
\hline Host & 1 & 1.846 & 30.92 & $* * *$ \\
\hline Cross $\times$ host & 2 & 1.349 & 22.59 & $* * *$ \\
\hline Error & 40 & 0.060 & & \\
\hline \multicolumn{5}{|l|}{ A. artemisiifolia } \\
\hline Source & d.f. & MS & $F$ & $P$ \\
\hline Cross & 2 & 0.179 & 2.98 & ns \\
\hline Error & 40 & 0.060 & & \\
\hline \multicolumn{5}{|l|}{ I. frutescens } \\
\hline Source & d.f. & MS & $F$ & $P$ \\
\hline Cross & 2 & 1.431 & 23.85 & *** \\
\hline Error & 40 & 0.060 & & \\
\hline
\end{tabular}

NTL, Ophraella notula; SLB, O. slobodkini.The data are the square root transformed proportions surviving to 15 days in each rearing container.

Two-way ANOVA with interaction was performed where the mating cross $(\mathrm{SLB} \times \mathrm{SLB}, \mathrm{SLB} \times \mathrm{NTL}$, NTL $\times \mathrm{NTL}$ ) and host plant species (A. artemisiifolia and I. frutescens) are fixed factors.

Means and standard errors are for untransformed proportion surviving.

Numbers in parentheses are sample sizes (the number of replicate rearing containers).

Means with the same letter are not significantly different by Tukey's test for unplanned comparisons from one-way ANOVAS for each host separately on the transformed data. The one-way ANovas use the $\mathrm{MS}_{\text {error }}$ from the two-way ANOVA.

${ }^{* *} P<0.01,{ }^{* * *} P<0.001$.

(c) The Genetical Society of Great Britain, Heredity, 76, 36-42. 
responses of hybrid larvae $(\mathrm{SLB} \times \mathrm{NTL})$ and those of homospecific crosses $(\mathrm{SLB} \times \mathrm{SLB}, \mathrm{NTL} \times \mathrm{NTL}$ ) indicate the near-ubiquity of strong dominance in both behavioural and physiological host-use traits. Hybrid larvae were not significantly different from one of the two parental species in their responses to $A$. artemisiifolia and $I$. frutescens. In both host preference and larval consumption (no-choice) of $A$. artemisiifolia, hybrid larvae resembled $O$. slobodkini, the maternal species that naturally uses $A$. artemisiifolia. Interestingly, however, for larval consumption (no-choice) of $I$. frutescens, and for larval survival, the hybrids resembled $O$. notulata, the paternal species that naturally uses $I$. frutescens. Thus hybrid larvae are capable of utilizing both $A$. artemisiifolia and $I$. frutescens although preference for $A$. artemisiifolia appears to be dominant. Maternal effects are not likely in this system on the basis of results of a previous study (Futuyma et al., 1993a). Ophraella notulata whose parents were reared on either $A$. artemisiifolia or $I$. frutescens did not show any evidence for maternal effects on performance traits although there were some maternal $\times$ paternal interaction effects.

It is difficult to interpret genetically the data on the acceptability of the host plants to the hybrids and their parental species. Both independent inheritance of separate loci for each host and single locus models with dosage effects are compatible with the observed pattern of response. Clearer is the relationship between host preference and performance (larval survival). Hybrid larvae strongly resemble the maternal parent in host preference but strongly resemble the paternal parent in performance, suggesting that these traits are inherited independently. This is in agreement with results from laboratory and field studies (Keese, 1994) that show that $O$. notulata retains considerable ability to utilize $A$. artemisiifolia (the putative ancestral host, see Funk et al., 1995) and does, indeed, perform as well as $O$. slobodkini on this host for some host-use traits. Most of the evolutionary change associated with the host shift from Ambrosia to I. frutescens appears to have occurred in traits that are primarily behavioural in nature (Keese, 1994). This suggests that shifts to novel host plants may not be such a difficult hurdle for some phytophagous insects since behavioural traits are often believed to be evolutionarily more labile than physiological traits (e.g. Futuyma, 1986).

Because of the lack of data on $F_{2}$ and backcross progeny, the number of independently segregating loci involved in determining the dominance patterns that exist in the responses of the $F_{1}$ hybrids can not be estimated. Directional dominance has not, to my knowledge, been demonstrated for a host-use trait in phytophagous insects, although the phenomenon in general has been well established (Robinson et al., 1949; Gardner, 1963; also in Wright, 1968). It seems unlikely that such strong dominance as observed in this study could result from many loci, but it is not known whether it is the result of a single locus or directional dominance at a few loci.

The data reported here clearly show the importance of dominance (whether single locus or multilocus directional) in the inheritance of host-use traits. Analyses of $F_{1}$ hybrids between the coccinelid beetles Epilachna niponica and E. yasutomii on the parental hosts (thistle and blue cohosh, respectively) also show dominance in host-use traits (Katakura \& Hosogai, 1994). These results have important implications for theories of host range evolution that assume additive polygenic control of host-use traits (Rausher, 1993) and many models of sympatric speciation that assume that host preference and performance are controlled by single loci (Maynard Smith, 1966; Bush, 1969).

More empirical studies of the underlying genetic control of host use traits in many different groups of phytophagous insects are needed. We need to know whether such patterns of dominance are typical, relatively common or rare. We also need more detailed studies of species that permit the analysis of $F_{2}$ and backcross data to establish whether any observed dominance is the result of single locus genetic inheritance or multilocus directional dominance. The answers to these questions will greatly enhance our understanding of how host plant associations evolve.

\section{Acknowledgements}

I thank the staffs of Tall Timbers Research Station, Tallahassee, FL, and St. Marks National Wildlife Refuge, St. Marks, FL, for permission to collect specimens. D. J. Futuyma, B. L. Bentley, W. Eanes and C. Janson provided valuable assistance on many aspects of this study. J. Jaenike, T. K. Wood and K. Tilmon and two anonymous reviewers provided valuable comments on an earlier version of this manuscript. This work was supported by NSF Dissertation Improvement Award BSR-911181 to the author and D. J. Futuyma. This is contribution 931 of the Department of Ecology and Evolution, SUNY at Stony Brook.

\section{References}

BUSH, G. L. 1969. Sympatric host race formation and speciation in frugivorous flies of the genus Rhagoletis 
(Diptera: Tephritidae). Evolution, 23, 237-251.

DENSO, P. 1909. Contribution à l'étude des sphingides hybrides paléarctiques. Bulletin of the Lepidoptera Society Genève, 1, 295-319.

DETHIER, V. G. 1954. Evolution of feeding preferences in phytophagous insects. Evolution, 8, 33-54.

FIELD, w. L. w. 1914. Hybrid butterflies of the genus Basilarchia. Psyche, 21, 115-117.

FUNK, D. J., FUTUYMA, D. J., ORT1, G. AND MEYER, A. 1995. A history of host associations and evolutionary diversification for Ophraella (Coleoptera: Chrysomelidae); mitochondrial DNA and total evidence. Evolution (in press).

FUTUYMA, D. J. 1986. The role of behavior in host-associated divergence in herbivorous insects. In: Huettel, M. D. (ed.) Evolutionary Genetics of Invertebrate Behavior: Progress and Prospects, pp. 295-302. Plenum Press, New York.

FUTUYMA, D. J. 1991. A new species of Ophraella Wilcox (Coleoptera: Chrysomelidae) from the southeastern United States. J. N.Y. Ent. Soc., 94, 643-653.

FUTUYMA, D. J., AND PETERSON, s. C. 1985. Genetic variation in the use of resources by insects. Ann. Rev. Ent., 30, 217-238.

FUTUYMA, D. J. AND PHILIPPI, T. E. 1987. Genetic variation and covariation in responses to host plants by Alsophila pometaria (Lepidoptera: Geometridae). Evolution, 41, 269-279.

FUTUYMA, D. J., HERRMANN, C., MILSTEIN, S. AND KEESE, M. C. 1993a. Apparent transgenerational effects of host plant in the leaf beetle Ophraella notulata (Coleoptera: Chrysomelidae). Oecologia, 96, 365-372.

FUTUYMA, D. J., KEESE, M. C. AND SCHEFFER, S. J. 1993b. Genetic constraints and the phylogeny of insect-plant associations: responses of Ophraella communa (Coleoptera: Chrysomelidae) to host plants of its congeners. Evolution, 47, 888-905.

GARDNER. C. O. 1963. Estimates of genetic parameters in cross-fertilizing plants and their implications in plant breeding. In: Hanson, W. D. and Robinson, H. F. (eds) Statistical Genetics and Plant Breeding, pp. 225-252. National Academy of Sciences, Natural Resource Council publ. no. 982.

HAGEN, R. H. 1990. Population structure and host use in hybridizing subspecies of Papilio glaucus (Lepidoptera: Papilionidae). Evolution, 44, 1914-1930.

HARRISON, J. W. H. 1926. On the inheritance of food habits in the hybrids between the geometrid moths Poecilopsis pomonaria $\mathrm{Hb}$. and $P$. isabella Harrison. Proc. Univ. Durham Phil. Soc., 7, 194-201.

JAENIKE, J. 1989. Genetic population structure of Drosophila tripunctata: patterns of variation and covariation of traits affecting resource use. Evolution, 43, 1467-1482.

KAROWE, D. N. 1990. Predicting host range evolution: colonization of Coronilla varia by Colias philodyce (Lepidoptera: Pieridae). Evolution, 44, 1637-1647.

KATAKURA, H. AND hosogal, T. 1994. Performance of hybrid ladybird beetles (Epilachna spp.) on the host plants of parental species. Entomologia. exp. appl., 71, $81-85$.

KEESE, M. C. 1994. Genetic and Ecological Determinants of Host Range in Leaf Feeding Beetles (Coleoptera: Chrysomelidae). Ph.D. Dissertation, SUNY at Stony Brook, Stony Brook, NY.

KIBOTA, T. T. AND COURTNEY, S. P. 1991. Jack of one trade, master of none: host choice by Drosophila magnaquinaria. Oecologia, 86, 251-260.

maynard smith, J. 1966. Sympatric speciation. Am. Nat., 100, 637-650.

RAUSHER, M. D. 1993. The evolution of habitat selection III. The evolution of avoidance and counter resistance. In: Kim, K. C. (ed.) Evolution of Insect Pests: The Pattern of Variations, pp. 259-283. John Wiley, New York.

ROBINSON, H. F., COMSTOCK, R. E. AND HARVEY, P. H. 1949. Estimates of heritability and the degree of dominance in corn. Agron. J., 141, 353-359.

SCHNEIDER, J. C. AND ROUSH, R. T. 1986. Genetic differences in oviposition preference between 2 populations of Heliothis virescens. In: Huettel, M. D. (ed.) Evolutionary Genetics of Invertebrate Behavior: Progress and Prospects, pp. 163-172. Plenum Press, New York.

SCRIBER, J. M., GIEBINK, B. L. AND SNIDER, D. 1991. Reciprocal latitudinal clines in oviposition behavior of Papilio glaucus and P. canadensis across the Great Lakes hybrid zone: possible sex-linkage of oviposition preference. Oecologia, 87, 360-368.

SINGER, M. C. 1986. The definition and measurement of oviposition preference in plant-feeding insects. In: Miller, J. R. and Miller, T. A. (eds.) Insect-Plant Interactions, pp. 65-95. Springer, New York.

SOKAL, R. R. AND ROHLF, F. J. 1981. Biometry, 2nd edn. Freeman, New York.

THOMPSON, J. N. 1988. Evolutionary genetics of oviposition preference in swallowtail butterflies. Evolution, 42, $1223-1234$.

THOMPSON, J. N., WEHLING, W. AND PODOLSKY, R. 1990. Evolutionary genetics of host use in swallowtail butterflies. Nature, 344, 148-150.

VIA, s. 1984a. The quantitative genetics of polyphagy in an insect herbivore. I. Genotype-environment interaction in larval performance on different host plant species. Evolution, 38, 881-895.

VIA, s. 1984b. The quantitative genetics of polyphagy in an insect herbivore. II. Genetic correlations in larval performance within and among host plants. Evolution, 38, 896-905.

VIA, s. 1986. Genetic covariance between oviposition preference and larval performance in an insect herbivore. Evolution, 40, 778-785.

WALDVOGEL, M. AND GOULD, F. 1990. Variation in oviposition preference of Heliothis virescens in relation to macroevolutionary patterns of Heliothis host range. Evolution, 44, 1326-1337.

WRIGHT, s. 1968. Evolution and the Genetics of Populations, vol. 1, Genetic and Biometric Foundations. University of Chicago Press, Chicago.

(C) The Genetical Society of Great Britain, Heredity, 76, 36-42 